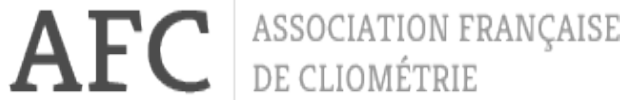

Nr. 10, 2012

Convergence Dynamics of Output:

Do Stochastic Shocks and Social

Polarization Matter?

Mamata PARHI, Claude DIEBOLT,

Tapas MISHRA, Prashant GUPTA 


\title{
Convergence dynamics of output: Do stochastic shocks and social polarization matter?
}

\author{
Mamata Parhi ${ }^{1 *}$, Claude Diebolt ${ }^{2}$, Tapas Mishra ${ }^{1}$, Prashant Gupta ${ }^{1}$ \\ ${ }^{1}$ Department of Economics \\ Swansea University, Swansea, UK \\ ${ }^{2}$ Bureau of Economic Theory and Applications \\ University of Strasbourg, \\ Strasbourg, France
}

\begin{abstract}
This paper seeks to address two neglected aspects of convergence dynamics of crosscountry per capita income. First, we allow evolutionary path of per capita income to contain stochastic shocks which may not converge fast enough to the long-run mean. Under this condition, we show that the conventional inference on $\sigma$ convergence can be enlarged with more predictive power if one assumes, along with the necessary condition of $\beta$ convergence, that the stochastic shocks are covariance stationary. Second, we argue that for economies to (conditionally) converge, they need to be sufficiently cohesive so that the growth of stochastic shocks is not sustained through complex socio-economic interactions. Empirical examination is carried out by analyzing time series properties of state per capita income in India and performing convergence analysis by conditioning a constructed social cohesion index based on indicators collected from the National Sample Survey. It is demonstrated that when the economy faces monotonic social segmentation, persistence of stochastic shocks considerably affect speed of per capita output convergence.
\end{abstract}

Key words: Social cohesion, convergence dynamics, long-memory, social distance, non-linear convergence speed.

JEL classification: C14, O40, O53.

\footnotetext{
*Corresponding author: Mamata Parhi [Department of Economics, Richard Price Building, Singleton Park, Swansea University, Swansea, SA2 8PP, UK; E-mail: m.parhi@swansea.ac.uk]; Tapas Mishra: t.k.mishra@swansea.ac.uk; Claude Diebolt: cdiebolt@unistra.fr; Prashant Gupta: prashant.prashant@hotmail.com
} 


\section{Introduction}

Both traditional theory of output convergence (based on the celebrated Solow-Swan model) and its recent extension (following on the success of endogenous growth theory) suffer from the important limitation that the relevance of slowly convergent shocks to the long-run mean is disregarded while outlining conditions under which (conditional) $\beta$ and $\sigma$ convergence $^{1}$ may occur among nations. Indeed, if one integrates literature from economic history, political economy, sociology and economic growth, one would find that non-mean convergent stochastic shocks are often found to be present in a segregated and socially alienated society and their magnitude of persistence is often found to be higher in the former than in a socially cohesive and stable society.

Presence or absence of convergence is not a completely economic phenomenon. If individuals' productivity in economic sense matter for aggregate national productivity, then it is essential to recognize the importance of social condition of individuals (i.e., if they are cohesive or alienated) under which they produce. Relative social position of individuals ${ }^{2}$ does affect productivity in a relative sense as individuals interacting in a stable and sustainable society produce externalities which are both socially and economically beneficial (for a recent survey, see for instance, Clark et al., 2008). The equilibria reached at under such societies are indicative of the high level of productivity growth which distinguishes itself from the outcome of a segregated society.

The sparse empirical studies have shown that polarized societies, as measured by ethnic fractionalization or income inequality, seem to be more prone to adopting growth-retarding policies. Moreover, social polarization may not only be responsible for coordination failure but is often thought to be associated with socio-political instability, which is by itself harmful to growth (e.g., Alesina et al., 1999). Majority of research, debates and policy discussions thus far have concentrated on developed societies, offering very little insights both with respect to rigorous theoretical and empirical analyses. In an era of rapid globalization and high internationalization of world economies, the effect of social polarization can have serious consequences for developing economies, especially because these economies' immediate objective is to achieve high growth and to be on the quality ladder of growth-success of developed economies. Second, some developing economies lend excessive emphasis on high growth for strategic political gains and building an effective deterrent to security threats from neighbors. In either case, growth without social limit is unstable and unsustainable.

In addition, even if one compares the optimization objectives of developed and developing worlds, the principal motive appears to remain the same, i.e., optimize growth subject to resource constraints along with securing a cohesive society, developing economies like India, face additional challenges. However, the priorities differ significantly for developing countries for two important reasons. First, along the growth trajectory, it is always difficult to jointly optimize growth and social cohesion ${ }^{3}$ especially when the growth trajectory concerns pure economic gains from achieved convergence for developing economies. Second, once a steady state growth is achieved and high growth momentum is maintained (as in most developed economies), the joint optimization of growth and cohesion becomes relatively easier since the social planner needs to focus more on re-distribution of resources in the society to make it more stable and cohesive. In view of these unique reasons, it is necessary to understand how persistent lack of cohesion in

\footnotetext{
${ }^{1}$ Broadly, when the dispersion of real per capita income across a group of economies falls over time, there is $\sigma$ convergence. When the partial correlation between growth in income over time and its initial level is negative, there is $\beta$ convergence.

${ }^{2}$ That is, whether some individuals enjoy more social benefit, for example, in terms ethnic or caste based status leading to availability of greater economic opportunities

${ }^{3}$ We follow Chan et al. (2006) and define social cohesion 'as a state of affairs concerning both the vertical and the horizontal interactions among members of a society, as characterized by a set of attitudes and norms that include trust, a sense of belonging, and willingness to participate and help, as well as the behavioural manifestations'.
} 
developing economies affects both short and long-run objectives of high and sustainable growth. Akerlof (1997) and Gradstein and Justman (2002) argued that individuals' utility in a society are interdependent and such interdependence generate externalities which can be both beneficial and counterproductive depending on whether high interdependence is facilitated among individuals who are polarized in the society or among those who are higher up in the social ladder. This microeconomic result has important implication for macroeconomic theory of convergence - that convergence of per capita income at cross-country level needs to be conditioned on social classes and distinctions. Arguably, socially cohesive societies create favourable conditions, for instance via education, whereas segmented societies tend to alienate themselves from optimum growth. Additionally but importantly, a stochastic shock always finds its way to long-run persistence in a transition and socially volatile than in a developed and relatively stable society. This is because segmented societies possess innate ability to endogenize stochastic shocks which can survive period after period unless the society moves up the in the cohesion ladder. Nonetheless, it is the nature of the survivability of shocks which can impact the extent and speed of convergence. To the knowledge of the authors, this aspect of convergence dynamics has not yet been studied in the literature.

The empirical analysis is carried out for India where we examine the convergence properties of state real GDP per capita over two decades. Among several developing countries, India is a unique case because of persisting high growth momentum and equally widening social inequalities. Growth without proper re-distribution among various strata of society in India has provided impetus to recent debates and discussion both in academic and policy circles. Based on our theoretical arguments, it will be interesting to study convergence in state per capita GDP while high degree of social alienation and stochastic shocks are allowed to be persistent. There is a growing number of studies in India that have focused on the issue of regional growth and convergence in per capita real income across the states (see for instance, Aiyer, 2001; Bandopadhyay, 2011; Sinha and Sinha, 2000). Bandopadhyay (2011), and Bandopadhyay (forthcoming), for instance, employ both non-parametric and parametric methods to examine convergence dynamics and Aiyer (2001) employs panel data technique to examine convergence hypothesis. These and similar other studies employ a variety of methodological tools (e.g., panel unit root, cointegration, stochastic kernel density, etc.) which disregard the effects of slow and non-mean converging stochastic arising from higher social segmentation. This paper aims to fill this void in the literature.

Although our emphasis would be on demonstrating how convergence speed is determined by social segmentation, the implications of our finding would be straightforward. As we will argue in the paper, alienated societies nurture non-mean convergent shocks more than highlyconvergent shocks. The latter is a characteristic feature of cohesive societies. To inhibit the proliferation of stochastic shocks it is essential that the economies and societies need to be stable and increasingly cohesive, which in the long-run help in achieving desirable convergence speed across sectors. To explicate further, we first build an analytical model by extending the conventional framework of convergence by mixing micro foundation to the macro setting (section 2 ). In the next step, we provide methods of testing such convergence (section 3). Empirical analysis carried out by studying inter-regional convergence pattern for India is presented next (in section 4). Finally in section 5, we conclude with main implications of our analytical and empirical results.

\section{Framework}

In this section, we build a simple model describing the interrelationship between social segmentation and economic growth convergence. We demonstrate that socially fragmented economies experience higher persistence of shocks than socially cohesive societies and that the magnitude of shock persistence determines the convergence rate of economies. Although the framework we describe is applicable in cross-country setting, it can be better understood within a regional 
economy framework of a nation, because elements of a subset are assumed to share affinities within a broader set. The agents within the set are expected to experience common steady behavior mainly due to their 'closeness' defined in both geographic and relational sense.

However, exceptions may occur and by utilizing the argument of social conditioning theory, divergence is a meaningful possibility in the sense that agents, even in a 'close' society maintain individualities. To the extent they internalize private and public information on their social standing, divergence of growth may occur. In this case, divergence, rather than convergence may be growth-enhancing and welfare maximizing. Such divergence may not create a chaotic and segregated society if the individuals compete in terms of productivity and knowledge-enhancement. However, human mind is seldom consistently affixed to idealistic states. Comparison does arise in human mind about their relative social and economic position. The competition and growth resulting from such a state may push the economy to low-level equilibrium trap, unless the social planner employs an equitable distribution plan over time. This argument has been stressed in Akerlof (1997) and Gradstein and Justman (2002) and has been the central argument among public policy analysts.

For the purpose of motivating our model, assume that the productivity, $A$ of an individual $i: i=(1, \ldots, n)$ is a function of his relative position in the society, denoted by utility $U$, and stochastic shocks (both endogenous and exogenous) $\left(\epsilon_{t}\right)$ present at time point $t: t=(1, \ldots, T)$ of the economy. The individuals are assumed to enjoy both complete private and public information about his relative socio-economic position. This information set is denoted by $\Omega$. Additionally assume that each individual is endowed with initial level of human capital $h_{0}$ and accumulated human capital denoted as $H_{t}=h_{0}+e^{\lambda t}$, where $\lambda$ is the efficiency gained over time through and the growth of human capital is denoted by $e^{\lambda t}{ }^{4}$ Thus, at time $t$, the productivity, $A$ of individual $i$ can be defined by

$$
A_{i t}=F\left(U_{i t}, H_{i t} ; \Omega\right)
$$

where $U_{i t}=-a x_{i t}^{2}+b x_{i t}+c-d\left(x_{i t}-\bar{x}\right)^{2}$. Denoting $x$ as the consumption unit or the status producing variable, the person loses utility of the amount $d\left(x_{i t}-\bar{x}\right)^{2}$ for failing to conform to the status of others high in the social strata. Following Akerlof (1997), this defines the relative social distance of the individual $i$ affecting his productivity level $A$ at time $t$. Moreover, $x$ is assumed to have an additional intrinsic utility of $a x^{2}+b x+c$, which is of quadratic structure conforming thus to the peculiarities of utility maximization theory. Since the utility function is of quadratic form, there would be only one equilibrium value of $x$, which occurs at $x=b / 2 a$. The problem confronting each individual $i$ is to choose $x_{i}$ contingent upon his initial social position, $x_{0}$ and his initial human capital, $h_{0}$. The individual must form expectations about the position of his potential competitor in social exchange. With static expectations where the acquired social position of all the other individuals will coincide with their initial positions, individual $i$ 's expected distance between himself and $j$ will be $\left|x_{i}-x_{0 j}\right|$. Denoting the initial social distance between individuals $i$ and $j$ as $d_{i j}^{e}$, it also defines the expected value of benefits in terms of productivity differential between $i$ and $j$. While aggregated over individuals and over time, it would mean that the economy with large number of population and segregated according to classes and demography will invariably find themselves trapped under a catching up problem. The problem becomes acute in the presence of stochastic shocks which survive certain period and affect various segments of the society.

In line with conventional theory we construct now an output growth (loosely defined by per capita output) process which conditions expected social distance, $d_{i j}^{e}$ and the information set, $\Omega$.

Definition 1 Conditional convergence in productivity: The per capita output $Y$ of state $S$ and $P$ converges if the long-term forecast of their difference conditional on $d^{e}$ and $\Omega$ is zero

\footnotetext{
${ }^{4}$ At idealistic state, $h_{0}$ is assumed to be equal for all $i$ emphasizing thus on the direct influence of social planner in maximizing welfare via education policy.
} 
at time $t$ :

and its variance declines over time:

$$
\lim _{k \rightarrow \infty} E\left(Y_{S, t+k}-Y_{P, t+k} \mid d^{e}, \Omega\right)=0
$$

$$
\operatorname{var}\left(Y_{S, t+k}-Y_{P, t+k}\right)=\sigma<\infty
$$

This definition is similar to Bernard and Durlauf (1995) but with an important addition that expected social distance over some economic functional must be zero and that every individual obtains complete and same private and public information, that is lim $d^{e} \rightarrow 0$ in probability and $\Omega$ which is decomposed of private and public information makes history dependence irrelevant. However, an economy is a breeding ground of stochastic shocks, some of them do escape certain periods and make economic system volatile. When social segmentation is acute, stochastic shocks take long time to taper off. This can affect the convergence speed of output between $S$ and $P$ at time $t$. As an example, assume that the estimated convergence speed without persistent shock is $\lambda$. Then in the presence of slow convergence shock, denoted by say, $d$, the estimated convergence speed may now appear as $(\lambda+d)$, where depending on the value of $d$, the convergence speed can be over or underestimated in the conventional testing framework. Note that the persistence of stochastic shocks and the convergence speed may vary significantly between exogenous and endogenous growth theoretic mechanisms. However, the analysis is beyond the scope of this research. For the purpose of this paper, we outline below a simple model which illustrates the importance of convergence speed of shocks for cross-country/regional productivity convergence. To motivate, we draw on Sala-i-Martin (1996) and Young et al. (2008). However, we extend the framework to long memory setting.

Since empirical studies often use natural logarithmic scale of per capita GDP, $\ln \left(Y_{i t}\right)$, we state the following dynamics

$$
\ln \left(Y_{i t}\right)=\alpha_{i}+(1+\beta) \ln Y_{i, t-1}+\Pi X_{i}^{\prime}+\epsilon_{i t}
$$

Manipulating (2) yields,

$$
\ln \left(Y_{i t} / Y_{i, t-1}\right)=\alpha_{i}+\beta \ln Y_{i, t-1}+\Pi X_{i}^{\prime}+\epsilon_{i t}
$$

where $i=1, \ldots, N, \epsilon_{i t} \sim \operatorname{iid}\left(0, \sigma_{u}^{2}\right), \alpha$ is fixed country effects and $X s$ are control or conditioning variables. In (3), a negative $\beta$ means that convergence in output growth holds conditional on the defined distance and information set. From (3) the heterogenous steady-states are given by $-\frac{1}{\beta}\left(\Pi X_{i j}^{\prime}+\alpha_{j}\right)$. Using the variance of log income for all states for each time period $t$ (where $\sigma_{t}^{2}$ $=\mathrm{E}\left[\ln \left(Y_{i t}-\mathrm{E}\left(\ln \left(Y_{i t}\right)\right)^{2}\right]\right)$ :

$$
\sigma_{t}^{2}=\left(\frac{1}{N}\right) \sum_{i=1}^{N}\left[\ln \left(Y_{i t}\right)-\mu_{t}\right]^{2}
$$

where $\mu_{t}=\mathrm{E}\left[\ln \left(Y_{i t}\right)\right]$ is the sample mean of log income. The sample variance approximates income variance when $N$ is large. We now use (2) and (4) to describe the evolution of $\sigma_{t}^{2}$ :

$$
\sigma_{t}^{2} \cong(1+\beta)^{2} \sigma_{t-1}^{2}+\sigma_{u}^{2}
$$

The implication is that the cross-state variance of income at time $t$ depends on its value at $t-1$ plus the cross-state variance of the idiosyncratic error, $u$. In (5) the system is difference equation stable only if $\beta<0$. That is, average income growth rates of backward economies are definitely greater than those of the advanced economies, which is empirically well-supported. However, allowing for different values for $\alpha$ and $X_{i}, \beta<0$ would imply conditional $\beta$-convergence. Intuitively, this indicates that the average growth rate of income of an economy is an increasing 
function of its distance from its balanced growth level of income. Given $-1<\beta<0$, the steady-state variance of income is given by,

$$
\left(\sigma^{2}\right)^{*}=\frac{\sigma_{u}^{2}}{\left[1-(1+\beta)^{2}\right]}
$$

Combining (5) and (6) one obtains,

$$
\sigma_{t}^{2}=(1+\beta)^{2} \sigma_{t-1}^{2}+\left[1-(1+\beta)^{2}\right]\left(\sigma^{2}\right)^{*}
$$

This is a first order difference equation with constant coefficients having the following solution:

$$
\sigma_{t}^{2}=\left(\sigma^{2}\right)^{*}+(1+\beta)^{2 t}\left[\sigma_{0}^{2}+\left(\sigma^{2}\right)^{*}\right]+\gamma(1+\beta)^{2 t}
$$

where $\gamma$ is an arbitrary constant. As long as $-1<\beta<0$, we have $|1+\beta|<1$ which implies that

$$
\lim _{t \rightarrow \infty}(1+\beta)^{2 t}=0
$$

Stability of $\sigma_{t}^{2}$ is ensured because it implies that,

$$
\lim _{t \rightarrow \infty} \sigma_{t}^{2}=\left(\sigma^{2}\right)^{*}
$$

The implication is that the variance will increase or decrease towards its steady state value depending on the initial variance $\sigma_{0}^{2}$.

We investigate next how slowly-decaying demographic shocks affect conditions for income convergence. For the purpose, we model state-specific income by an $I(m)$ process where fractional values of $m$, the integration parameter in the auto-covariance function (defined for lag length $k: G(k) \sim C(k) k^{2 m-1}$ as $k \rightarrow \infty$ and $C(k) \neq 0$ ) displays varying convergence rates of shocks. Recalling that the variance of income is calculated for all states taken together (that is for the cross-sectional terms) and for each time period $t$, one may obtain then the time series of cross-sectional variance for each time period. In this case $m$ represents the integration parameter such that if the value of $m$ is in the interval $[0.5,1)$ the series is nonstationary though mean reverting. If $m \geq 1$ it is nonstationary and non-mean reverting. Stationary (long memory) occurs if $m$ belongs to the interval $(0,0.5)$.

Proposition 1 When $\lim d^{e} \rightarrow 0$ and $m<1 / 2$, convergence in output between two economies is stable in the sense of $\sigma$ convergence in addition to the condition that $\beta<0$.

\section{Proof:}

For the purpose, we modify equation (7) and model temporal difference between $\sigma_{t}^{2}$ with a fractal structure:

$$
(1-L)^{m} \sigma_{t}^{2}=\left[(1+\beta)^{2}-1\right] \sigma_{t-1}^{2}+\left[1-(1+\beta)^{2}\right]\left(\sigma^{2}\right)^{*}
$$

where $L$ is the backshift operator and $d$ is the integration parameter such that $(1-L)^{m}$ can be approximated by binomial expansion and where $(1-L)^{m}=\sum_{j=0}^{\infty} h_{j} L^{j}$ with $h_{j}=(j+1)^{m-1}$ is the impulse-response function of the effect of stochastic shock. Re-writing (11), one obtains,

$$
\sigma_{t}^{2}=(1-L)^{-m}\left[(1+\beta)^{2}-1\right] \sigma_{t-1}^{2}+(1-L)^{-m}\left[\left[1-(1+\beta)^{2}\right]\left(\sigma^{2}\right)^{*}\right]
$$

The solution of this equation now appears as:

$$
\sigma_{t}^{2}=\sigma^{2(*)}+(1+\beta)^{2 t}(1-L)^{-m}\left[\sigma_{0}^{2}+\sigma^{2 *}\right]+\gamma(1+\beta)^{2 t}(1-L)^{-m}(1-L)^{-m}\left[\left[1-(1+\beta)^{2}\right]\left(\sigma^{2}\right)^{*}\right]
$$

Clearly, the stability of the above system, i.e., $\sigma$ convergence will occur not only with $-1<\beta<0$ but also with additional constraint that $m$ must be mean reverting, $-0.5<m \leq 0$. Therefore 
economies can be $\beta$ converging in income growth towards one another while, at the same time, random shocks would push them apart. However, if $m>1 / 2$, persistence in social alienation continues, that is, the expected distance $d^{e}$ in the society grows monotonically. Q.E.D

It should be noted from the above that stability condition (both with and without stationary long-memory shocks) holds true on the condition that the society is stable and cohesive enough to disallow slow or non-convergence of shocks to the long-run mean. When $d^{e}$ increases monotonically (limit being 1 ), $\sigma$-convergence may not occur even with $\beta$ being negative as the segmented society becomes the breeding ground for the proliferation of shocks, which ultimately pushes the economy to the low-level equilibrium. Under this condition, one can imagine three types of situation: first, a stable and cohesive society, where normal conditions of convergence prevail (that is $m<1 / 2, d^{e}=0$, and $\beta<0$ ) so that inter-regional/country differences in dispersion in income decline monotonically. Second, there would be a socially segmented society, facing chaotic economic dynamics, where divergence, rather than convergence is the possibility. Third, there are economies in transition, which over a time duration have experienced a transition of $d^{e}$ from 1 (alienation) towards 0 (cohesion), and the long-memory shock, $m$ transiting from $>1 / 2$ (non-stationary long-memory) to $<1 / 2$ (stationary long-memory). In the following section, we construct an empirical test of convergence based on stochastic long-memory classification as well as their transitional dynamics.

\section{Convergence tests}

In this section, we discuss three main test procedures that account for the presence of slow and non-mean convergence rate of stochastic shocks, transitional dynamics, and the extent of non-linearity in the understanding of speed of convergence in output.

\subsection{Stochastic long-memory and output convergence}

A common test of convergence often employed in empirical growth literature is to study the temporal properties of per capita output. To this effect, one can employ either (semi-)parametric or non-parametric approaches. In what follows, we will discuss the (semi-)parametric approach to estimate the speed of convergence first. Second, an outline of the recent development in non-parametric domain, viz., non-linear half-life will be provided to obtain information on the local convergence speed of output.

The literature concerning test of convergence in parametric follows two principal approaches: first, the coefficient of the initial level of output $(\beta)$ in explaining per capita output growth between period $t$ and $t+T$ ( $T$ being sufficiently large) is negative. An analogous empirical test procedure often employed in this setting is to investigate if multivariate output series contain stochastic unit root, that is whether they follow common stochastic trend. An alternative way is to classify the cross-sectional output series into convergence classes of shocks (that is if subsets of states are characterized by stationary long-memory, short-memory, and nonstationary long-memory). Since each of these classes possesses distinct transitional dynamics to steady state, long-memory convergence approach appear to fit most of the theoretical models and are intuitively akin to conventional empirical economic growth analysis. Since long-memory class of models accommodate the extreme cases of unit root and trend stationary processes, we employ this method for our empirical investigation.

A recent (semi-parametric) approach to test for long-memory is Shimotsu (2008) and Shimotsu and Phillips (2005). Let $I_{x}\left(\lambda_{j}\right)$ denote the periodogram of a series $x_{t}$ based on a discrete Fourier transform $F_{x}\left(\lambda_{j}\right)$ at frequency $\lambda_{j}=\frac{2 \pi j}{T}$ for $j=0, \ldots, T-1$ such that $I_{x}\left(\lambda_{j}\right)=$ 
$F_{x}\left(\lambda_{j}\right) F_{x}^{*}\left(\lambda_{j}\right)$ with $F_{x}^{*}\left(\lambda_{j}\right)$ being the complex conjugate of $F_{x}\left(\lambda_{j}\right)$ defined as

$$
F_{x}\left(\lambda_{j}\right)=\frac{1}{\sqrt{2 \pi T}}\left|\sum_{t=1}^{T} x_{t} e^{i t \lambda_{j}}\right|^{2}
$$

The discrete Fourier transform $F_{x}\left(\lambda_{j}\right)$ can be used to define a Whittle estimator of $d$ obtained by minimizing the objective function below with respect to $d$ :

$$
W(G, m)=\frac{1}{d} \sum_{j=1}^{\nu}\left(\ln \left(G \lambda_{j}^{-2 m}\right)+\frac{I_{x}\left(\lambda_{j}\right) \lambda_{j}^{2 m}}{G}\right), G \in(0, \infty)
$$

where $\nu$ is the number of frequencies used in the estimation. A well known Whittle estimator valid under non-stationarity is Exact Local Whittle (ELW) estimator of Shimotsu and Phillips (2005). This estimator has been shown to be consistent and has the same $N(0,1 / 4)$ limit values for all values of $d$. It is 'exact' because it relies on exact algebraic manipulation and is different from the conventional Local Whittle estimator which is based on an approximation of Whittle likelihood function and is not a good general-purpose estimator when the value of $d$ may take on values in the non-stationary zone beyond $\frac{3}{4}$. However, the ELW estimator has also been shown to possess some undesirable properties. As demonstrated in Shimotsu (2008), if an unknown mean (initial value) is replaced by its sample average, simulation suggests that the ELW estimator is inconsistent for $d>1$. Therefore we use the new estimator suggested by Shimotsu (2008): Feasible ELW (FELW), 2-step Feasible Exact Local Whittle (2FELW). These estimators are also computed with prior detrending (FELWD, 2FELWd) of data as suggested by Simotsu (2008). All LW, ELW, FELW, FELWD, 2FELW and 2FELWD estimators are used to estimate $d$ where $\nu$ is chosen as $\nu=T^{0.6}$ as suggested by Shimotsu (2008).

\subsection{Transitional dynamics in convergence test}

While the above test provides an idea about the extent of deviation of empirically established convergence speed from the non-mean convergent stochastic shocks, it was not possible to study the transitional dynamics that might affect the convergence speed. In view of this, in the next step, we look for common class in transitional dynamics among a set or subset of agents (which may be regions, states or countries). Phillips and Sul (2009) develop a nonlinear dynamic factor model of the form

$$
\log Y_{i t}=\alpha_{i t}+X_{i t} t=\beta_{i t} \mu_{t}
$$

where the component $\alpha_{i t}$ embodies transitional dynamics for real effective capital in the tradition of neoclassical growth model and the $X_{i t} t$ captures the idiosyncratic time paths of technological progress. The dynamic factor formulation $\beta_{i t} \mu_{t}$ involves a growth component, $\mu_{t}$, that is common across individuals, and individual transition factors $\left(\beta_{i t}\right)$ that measure how individual economic performance relates over time to $\mu_{t}$. In neoclassical growth framework, steady state common growth for $\log Y_{i t}$ may be represented in terms of a simple linear deterministic trend $\mu_{t}=t$. Then

$$
\beta_{i t}=X_{i t}+\frac{\alpha_{i t}}{t} \rightarrow X_{i} ; t \rightarrow \infty
$$

so that $X_{i}$ determines the growth rate of economy $i$ in the steady state. The quantity $\beta_{i t}$ therefore plays a key role as a transition parameter in this framework (see Phillips and Sul, 2009 for details). The finding of different convergence clubs in empirical analysis would imply that some societies within a given economy share common cohesion dynamics than others. The existence of such multiple equilibria also reflects the fact that targeted but not unique socio-economic policies can smooth out the effect of stochastic shocks and facilitate a normal convergence pattern. 


\subsection{Non-linearity and half-life}

In the previous two cases, we discussed how convergence speed may vary while one accounts for transitional dynamics of per capita output and the presence of non-mean converging stochastic shocks. Using these procedures, one can identify the cluster of countries (or regions) which share same pattern of growth. But, how does non-linearity affect the each country's (or states' within a country) convergence process? In the case of convergence of per capita income among various regions in a country, one would then try to understand if the presence of possible non-linear feedback and growth of stochastic shocks can determine the speed of convergence of output for each region is faster/slower than is empirically established. Moreover, we are also interested in understanding the adjustment process of real GDP per capita $\left(y_{t}\right)$ towards its long-run level $y$ provided that stochastic shocks are stationary and the economy is cohesive. Increasing deviations of $y_{t}$ from $y$ occurs when shocks transits from stationary to non-stationarity and the society becomes increasingly non-cohesive.

A note on the non-linear half-life and slow convergence of shocks is in order. First, nonlinear half-life indicates that stochastic shocks in output may be converging slower than expected and that such convergence pattern can be a feature of an increasingly polarized societies. Second, as argued before, polarized societies are highly probable places where stochastic shocks survive for a long period leading to high persistence of shocks and over estimation of convergence speed of income.

To understand this, we employ a non-linear half-life test for convergence (Shintani, 2006). Since 'half-life' is the most frequently used summary measure of persistence in the literature, we will mainly focus on this in the paper. The half-life of deviations in our case is the number of years required for the deviation at an initial level to dissipate by half. For an autoregressive process with long memory, the half-life can be defined by the derived impulse response function $\left[(1-\rho L)^{d}\right]^{h}=h / 2$, where $h=\ln (1 / 2) / \ln \left|(1-\rho L)^{d}\right|$ such that the half-life and the speed of convergence will not only depend on the sign and magnitude of $\rho$ but also on the convergence of $d$.

To accommodate non-linear features, we have assumed smooth transition autoregressive model (STAR) for $y_{t}$ such that $y_{t}$ could be described by the class of non-linear autoregressive (AR) models $y_{t}=F\left(y_{t-1}\right)+\varepsilon_{t}$ where $F\left(y_{t-1}\right)$ is a non-linear conditional mean function $E\left(y_{t} \mid y_{t-1}\right)$. Then, the non-linear impulse response function (IRF) is given by $\operatorname{IRF}_{n}\left(y_{0}, \delta\right)=$ $F_{n}\left(y_{0}+\delta\right)-F_{n}\left(y_{0}\right)$ where $\delta$ is the amount of shock to output series. The first derivative of the conditional mean function $F\left(y_{t-1}\right)$ is proportional to the one step ahead non-linear IRF for small

$\delta$, since $D F\left(y_{0}\right)=\lim _{\delta \rightarrow 0} \frac{F\left(y_{0}+\delta\right)-F\left(y_{0}\right)}{\delta}$, then local half-life at $y_{0}$ is defined by $h\left(y_{0}\right)=\frac{\ln (1 / 2)}{\ln \left|D F\left(y_{0}\right)\right|}$. This measure is used in the empirical section to provide the rate and shape of convergence of $y_{t}$ to its long-run level.

\section{Empirical analysis}

In this section, we provide results of convergence tests based on the methods discussed in Section 3. The speed of convergence will be analyzed in light of the social and transitional dynamics, the analytical framework of which has been outlined in Section 2. For the purpose of empirical illustration, we have used state level per capita GDP spanning over three decades (1970-2006). The data have been obtained from Reserve Bank of India for various years. As has been argued before, the choice of India for our empirical examination is important in light of recent growth success story, especially after the liberalization period initiated in 1991. The pre-liberalization period was marked by strict control and regulation. Along with income growth, the Indian society has also expressed rapid transition in terms of cohesion. Commentators have often argued that the high growth of income per capita has resulted in divided society having sharp distinction in income inequality over the years. To test if income convergence has occurred among the Indian states, we condition income growth according to social status, which is measured by 
education cohesion and a constructed measure based on consumption inequality (reflecting more of social, then economic characteristics). The latter measure also captures features of social distance argument forwarded by Akerlof (1997).

To lend social dynamics to convergence debate ${ }^{5}$, it is necessary to study how Indian economy has evolved over the years. We are interested here to understand if state per capita income growth has co-evolved with a rise/fall of social cohesion. A measure of cohesion is warranted. There has been vigorous attempts recently to build a unique measure of social cohesion which can preserve its multidimensionality. In the literature, a variety of direct or indirect measures and different proxies exist which help understand the cohesiveness in open societies. Some commonly used indices are measures of trust (Knack \& Keefer, 1995), income distribution (Rodrik, 1999; Easterly et al., 2006), ethnic heterogeneity or ethno-linguistic fractionalization (Easterly et al., 2006; Bossert et al. 2011) and discrimination in education, income and health (Esteban et al., 2012). While the data availability is a major issue in building a proper index of social cohesion in developing economies, viz., India, in this paper we utilize household consumption and educational disparity for the construction of the cohesion index. Our idea is that in a divided society like India, consumption pattern vary substantially across social strata and regions. Similarly, educational attainment differential among individuals can also reflect the extent of cohesiveness. Both the measures follow well-founded economic theoretic logic, such as Gradstein and Justman (2002).

Accordingly, in Table 1, we present the estimates of cohesion index based on per capita consumption expenditure and educational attainment levels obtained from the National Sample Survey (NSS) for two specific periods, viz., 1993 and 2004. One of the important ways to measure cohesion and social polarization would be to build an index based on per capita consumption and educational attainment distance. While the former is a convenient tool for welfare analysis, the usefulness of the latter has been recognized in the aftermath of endogenous growth theory's success.

The index for each category is calculated by inverting the value of $(x-\min ) /(\max -\min )$, where $x$ corresponds to state average consumption or education. max and min are maximum and minimum values corresponding to each category. It is expected that after liberalization, the social distance among states per capita consumption and educational level would decline over time. In Table 1, values greater than 0.5 represent polarization and less than 0.5 represent cohesiveness. It appears that for all states and union territories ${ }^{6}$, there has not been any significant differences in social cohesion between 1993-94 and 2004-05 although a marginal increase in the cohesion index is found for both consumption and educational based measures. Overall, it is evident that all Indian states and territories are characterized more by social alienation than by high degree of cohesion, although some states have fared relatively better (for instance, Punjab, Manipur and Kerala) than the rest. It will be interesting see, if this social classification contributes largely to the persistence of stochastic shocks, which eventually affects speed of convergence of state per capita GDP.

The distributional dynamics of social cohesion for 1993 and 2004 is presented in Figure 1. The left panel of Figure 1 presents Kernel density plots for social cohesion based on consumption expenditure distance for 1993 and 2004, whereas education based measure of social cohesion is presented in the right panel of Figure 1. The thick lines in each figure represents the estimated density which is plotted against normal distribution (thin lines) along with their distributed standard deviations. Two notable features emerge: first, the density plots of social cohesion based on both consumption and education are skewed to the right except the education based

\footnotetext{
${ }^{5}$ Note that the analysis is carried out for single country setting having multiple states. Obviously there is a spatial dimension to the convergence debate. However, this analysis while interesting is beyond the scope of the present study and can be reserved for future research.

${ }^{6} \mathrm{~A}$ Union Territory is an administrative division of India, in the federal framework of governance. Unlike the states of India, which have their own elected governments, union territories are ruled directly by the federal government.
} 
Table 1: Social Cohesion Index for 1993 and 2004

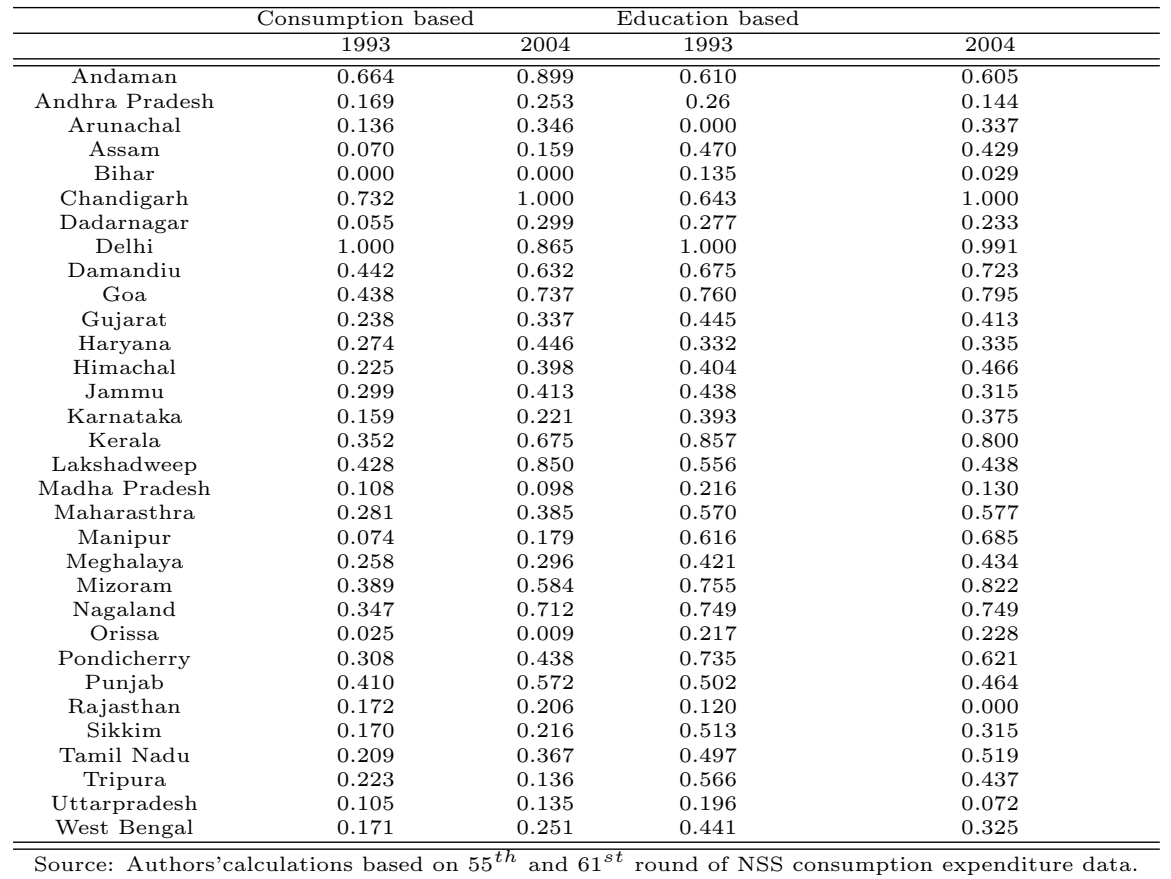

measure in 1993. Second, cohesion distributions for the year 2004 display distinct bi-modality, implying possible presence of convergence clubs/clusters. From no cluster in 1993 to distinct clusters in 2004 imply that the transitional dynamics in Indian society is getting concentrated on low-level and high-level equilibria trap. This feature may significantly affect convergence pattern of output, the analytical framework of which has been presented in Section 2. However, density plots may not fully capture the transitional dynamics of output from low to high level equilibrium. An alternative test procedure has been proposed by Phillips and Sul (2009). The results are presented in Table 2.

Phillips and Sul (2009) test of transitional dynamic behavior allows us to classify statelevel per capita output of Indian into cluster and sub-clusters. In Table 2, the overall test shows that the null of no convergence is rejected at 10 percent level. In the first club (see the column 2, headed initial classification) consists of four states where transitional dynamic component or fitted regression coefficient. All clubs have fitted coefficients which are negative (see the second column), thereby rejecting convergence and revealing evidence of divergence. For clubs 1 through 3, although point estimates are all significantly negative, they are also significantly less than 2.0. So there is strong evidence of conditional divergence and compelling evidence of level convergence within each of these clubs. The second panel reports the tests conducted to determine whether any of the original subgroups can be merged to form larger convergence clubs. We consider adjacent subgroups in the original classification and each cell in the panel reports the fitted regression coefficient and corresponding to heteroscedasticity and autocorrelation consistent (HAC) standard error. As can be observed the three sub-groups are taken to form separate convergence clubs. The results from transitional dynamics support our findings of long-memory characteristics, in that all major Indian states have been experiencing divergent growth processes, conditional of course on social dynamics. 

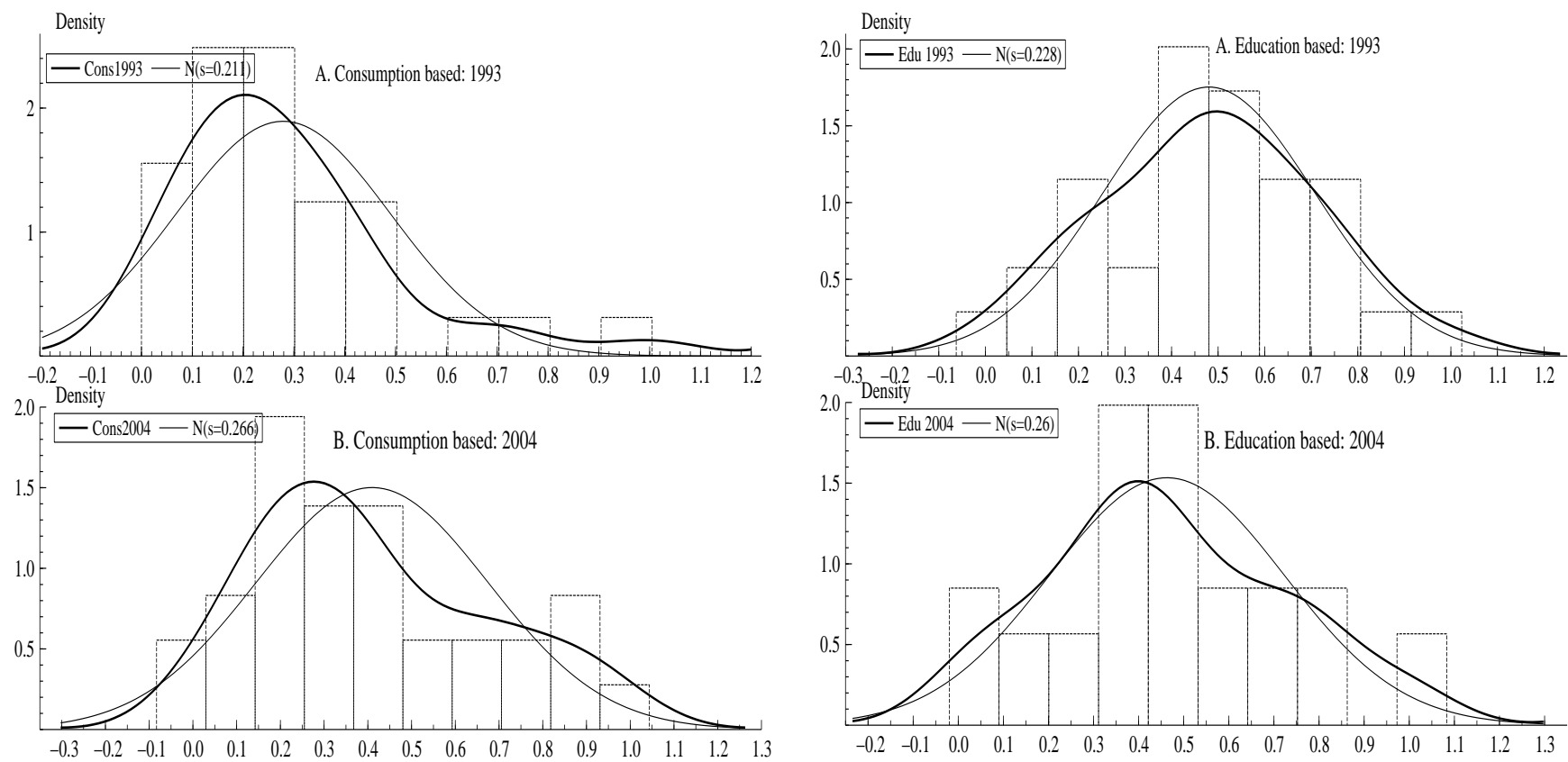

Figure 1: Distribution of cohesion index. [Left]: Consumption based. [Right]: Education based.

Table 2: Convergence and transitional dynamics

\begin{tabular}{lll}
\hline & Initial classification & Test of club merging \\
\hline Club 1 [4] & $-0.772(0.020)$ & club 1+2: $0.498(0.006)$ \\
Club 2 [5] & $-0.155(0.059)$ & club 2+3: 0.588 $(0.011)$ \\
Club 3 [7] & $-0.667(0.007)$ & \\
\hline
\end{tabular}

Note: Figures in parentheses (...) are HAC standard errors.

We next present results of long-memory test for 15 major Indian states for the period 1988-2006. For the purpose we report exact likelihood and its modification as in Shimotsu and Phillips (2005) and Shimotsu (2008). The results are presented in Table 3. Note that if the value of $d$, the integration parameter representing memory properties of per capita GDP, is less than 0.5 , we call this a short-memory or covariance stationary process. Values greater than 0.5 are long-memory and such shocks may take long-time to converge or may not converge at all. From Table 3, it is clear that the state per capita GDP for Punjab has long-memory value less than 0.5 , which implies that the income series is a stationary process. Comparing this value with the corresponding figure in Table 1, it is apparent that Punjab is one of the most consistent states in terms of social cohesion, the other being Kerala. Combining the results of long-memory in output and cohesion, it is thus apparent that highly cohesive societies contain stationary long-memory shock, the exception being Kerala. For the remaining states, both cohesion and long-memory estimates display 'polarization and volatile economies'.

As invoked in Section 1, an important issue that a researcher would like to understand is the convergence pattern of state per capita income to their own steady states conditional on stochastic shocks and social segmentation. A similarity of convergence pattern among states would indicate existence of possible clusters, sub-clusters, level convergence or divergence. As discussed in the preceding section, non-linear half-life convergence measure will be able to demonstrate the existence of such clusters. Our purpose would be to observe whether the speed of convergence is linear or non-linear. The finding of the latter would mean that the estimated convergence speed based on linearization principle around steady state income level may under- 
estimate the true value of convergence. Rather, the presence of non-linearity would imply the existence of social dynamics and slowly-converging stochastic shocks, which eventually make the speed of convergence slower than is empirically established.

Looking at the Figures (2-9), it is evident that except Assam (left panel of Figure 2), Haryana (left panel of Figure 4), and Punjab (left panel of Figure 7), none of the 12 states provide any evidence of linear local convergence. In fact, most states, for instance Andhra Pradesh (left panel of Figure 2), Gujarat (Figure 3) provide evidence of non-linear convergence till certain range and non-linear divergence for the rest. The combined presence of non-linear local convergence and divergence for any time series, such as per capita income implies that various structural economic-social processes are at work. It also provides evidence of structural change that has significantly affected the evolutionary pattern of growth of output. Looking at the results of convergence clusters and sub-clusters and the results of divergence from Table 2 , it is not surprising to find non-linearity and different local convergence speeds across Indian states. The results further strengthen our finding in Figure 1 about the bi-modality in the social cohesion distribution at the recent period. Taken together, it is evident that state level per capita income in India do not lend to unique convergence dynamics. Rather, persistent social dynamics and stochastic shocks are affecting the speed of convergence.

Table 3: 2-step feasible Exact Likelihood estimates of long-memory parameter

(Note: $H_{0}: \mathrm{d}=0$. The optimum chosen bandwidth $=0.60$.)

\begin{tabular}{ll}
\hline States & 2-step FELW \\
\hline Andhra Pradesh & 0.880 \\
Assam & 0.876 \\
Bihar & 1.169 \\
Gujarat & 1.139 \\
Karnataka & 0.674 \\
Haryana & 0.748 \\
Kerala & 0.942 \\
Madhya Pradesh & 1.257 \\
Maharasthra & 0.623 \\
Orissa & 0.630 \\
Punjab & 0.473 \\
Rajasthan & 0.874 \\
Tamil Nadu & 0.770 \\
Uttar Pradesh & 0.565 \\
West Bengal & 1.495 \\
\hline
\end{tabular}

\section{Conclusion}

In this paper, we studied properties of convergence dynamics of output while explicitly accommodating social distance and stochastic shocks in the determination of convergence speed. We integrated social choice, political economy and economic growth theory and provided analytical result showing that convergence of stochastic shocks in output is necessary for ensuring $\sigma$ convergence in output along with the condition that the social distance must be minimal and cohesion in the society is sustainable and stable. The central idea of the paper was to provide a micro foundation to the macro behavior of the economy where the edifice of the former rests on the relative social positioning of agents.

Our empirical results point at the capital importance of stochastic shocks by showing that per capita income among majority of Indian states have been diverging intrinsically with interesting transitional growth dynamics. The implication is that conditioning social distance in conventional convergence framework sheds new light into the stability of convergence and transitional dynamics of income growth over time. Moreover at the empirical level, this would 
suggest then that only some states are driving growth at the macroeconomic level and others are falling behind or stagnating, pointing thus at the existence of multiple equilibria in the income growth process. Our finding that there is no evidence of conditional convergence in state GDP per capita income is consistent with the broad literature which emphasizes on the crucial role of polarization in understanding dynamics of economic growth. One of the important conclusions of the paper is that persistent social polarization will decelerate the speed of convergence of income. It can be argued that this is true for any society, not just India, although it can be gauged from our discussion that developing societies are highly prone to social polarization and persistence of shocks than developed societies.

\section{References}

Aiyer, Shepherd (2001), "Growth Theory and Convergence across Indian States: A Panel Study", Chapter 8 in India at the Crossroads: Sustaining Growth and Reducing Poverty, ed. Tim Cullen, Patricia Reynolds and Christopher Towel, International Monetary Fund.

Akerlof, G.A. (1997), "Social Distance and Social Decisions", Econometrica, 65(5), 1005-1027.

Alesina, A., R. Baqir and W. Easterly (1999), "Public Goods and Ethnic Divisions", Quarterly Journal of Economics, 114: 1243-84.

Bandyopadhyay, S. (2011), "Rich States, Poor States: Convergence And Polarisation In India," Scottish Journal of Political Economy, Scottish Economic Society, vol. 58(3), 414-436, 07.

Bandopadhyay, S. (forthcoming), "Convergence clubs in incomes across Indian states: Is there evidence of a neighbours effect?", Economics Letters.

Bernard, A.B. and S.N. Durlauf (1995), "Convergence in International Output", Journal of Applied Econometrics, 10, 97-108.

Bossert, W., D'ambrosio, C. And La Ferrara, E. (2011), "A Generalized Index Of Fractionalization", Economica, 78 (312): 723-750.

Chan, J., T. Benny, and E. Chan (2006), "Reconsidering social cohesion: developing a definition and analytical framework for empirical research", Social Indicators Research, 75, 273-302.

Clark, A.E., P. Frijters and A.M. Shields (2008), "Relative Income, Happiness, and Utility: An Explanation for the Easterlin Paradox and Other Puzzles", Journal of Economic Literature, $46: 1,95144$.

Easterly, W., J. Ritzan, and M. Woolcock (2006), "Social Cohesion, Institutions, and Growth," Economics and Politics, 18(2), 103-120.

Esteban, J., L. Mayoral, and D. Ray. (2012), "Ethnicity and Conflict: An Empirical Study," American Economic Review, 102(4): 1310-42.

Gradstein, M. and M. Justman (2002), "Education, Social Cohesion, and Economic Growth," American Economic Review, 92(4), 1192-1204.

Knack, S. and Keefer, P. (1995), "Institutions and economic performance: Cross-country tests using alternative institutional measures," Economics and Politics, 7, 207-227.

Phillips, P.C.B. and D. Sul (2009), "Economic Transition and Growth", Journal of Applied Econometrics, 24, 1153-1185.

Rodrik, D. (1999), "Where did all the growth go? External shocks, social conflicts, and growth collapses", Journal of Economic Growth 4(4), 385-412. 
Sala-i-Martin, X (1996), "Regional cohesion: Evidence and theories of regional growth and convergence", European Economic Review, 40: 1325-1352.

Shimotsu, K. (2008), "Exact Local Whittle estimation of fractional integration with unknown mean and time trend", Econometric Theory, 26: 501-540.

Shimotsu, K. and P. C.B. Phillips (2005), "Exact local Whittle estimation of fractional integration", Annals of Statistics, 33: 1890-1933.

Shintani, M. (2006), "A nonparametric measure of convergence towards purchasing power parity," Journal of Applied Econometrics, 21, 589-604.

Sinha, T. and D. Sinha (2000), "No Virginia, States in India are NOT converging", International Indian Economic Association, Working Paper No. 2000-09-01.

Young, A.T., M.J. Higgins and D. Levy (2008), "Sigma-convergence versus beta-convergence: Evidence from US county level data", Journal of Money, Credit and Banking 40: 1083-1094. 


\section{Appendix}
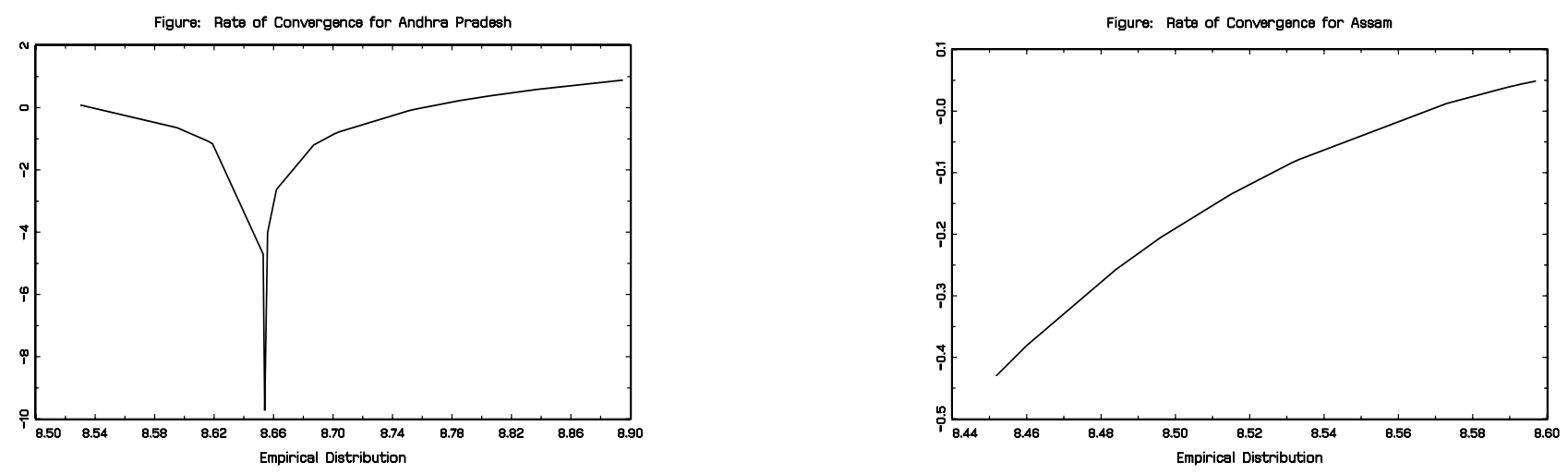

Figure 2: Local speed of convergence. [Left]: Andhra Pradesh. [Right]: Assam
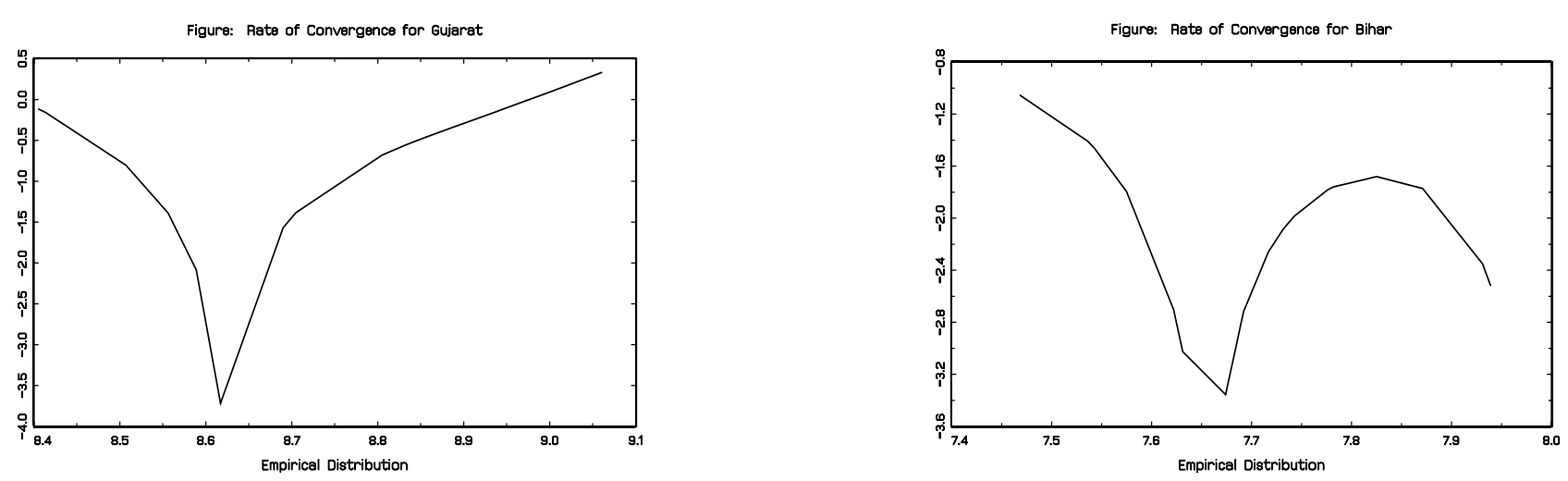

Figure 3: Local speed of convergence. [Left]: Gujarat. [Right]: Bihar 

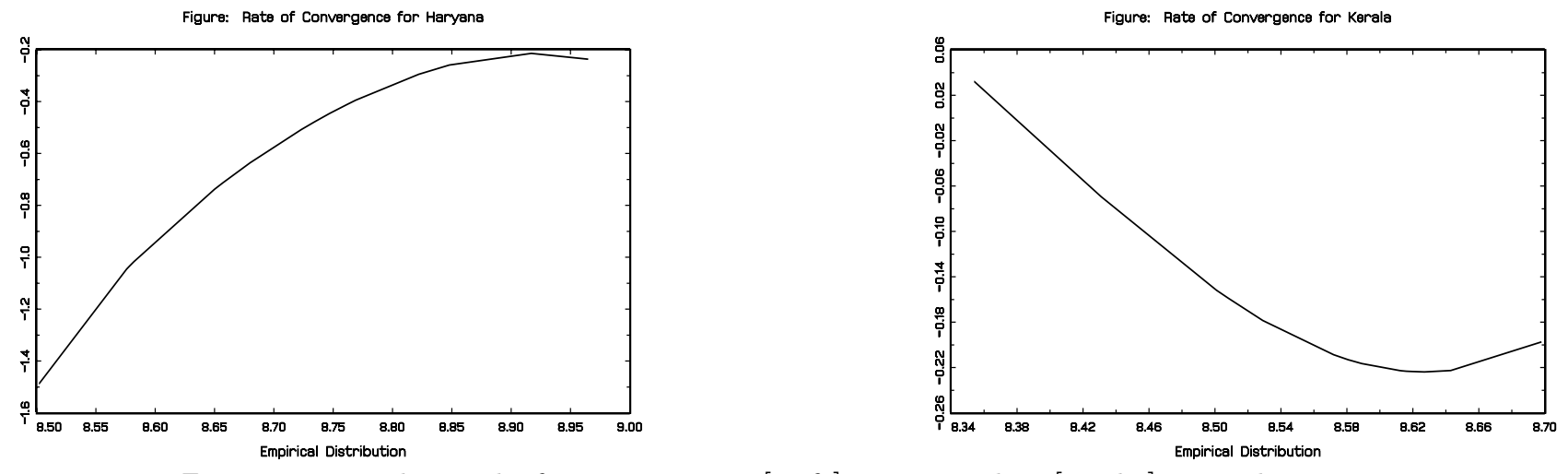

Figure 4: Local speed of convergence. [Left]: Karnataka. [Right]: Kerala
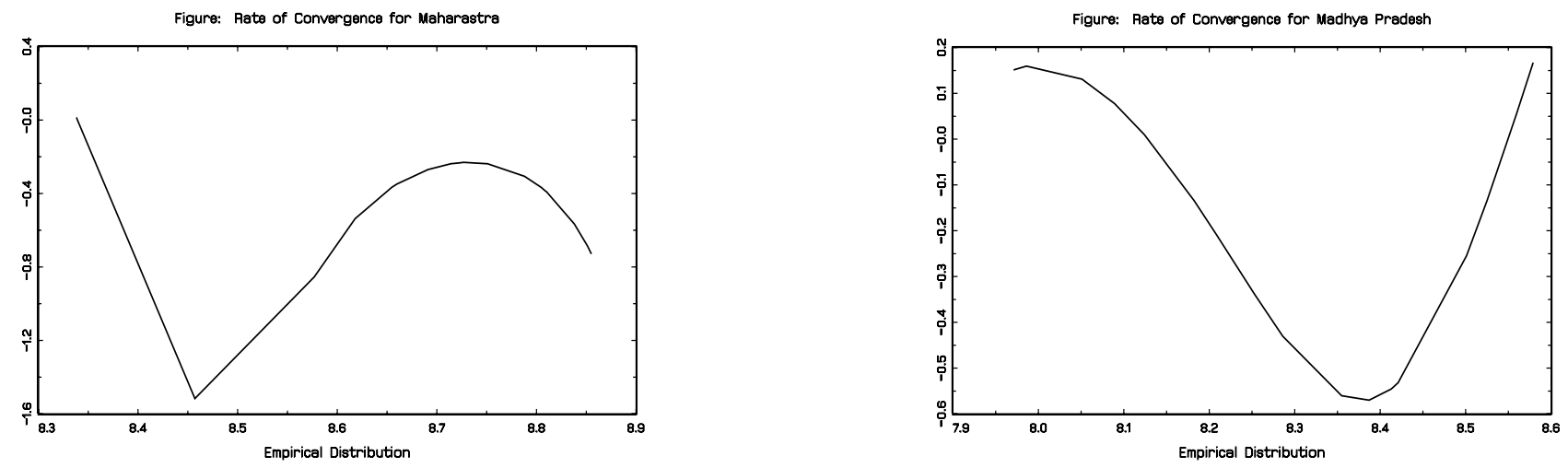

Figure 5: Local speed of convergence. [Left]: Maharasthra. [Right]: Madhya Pradesh 

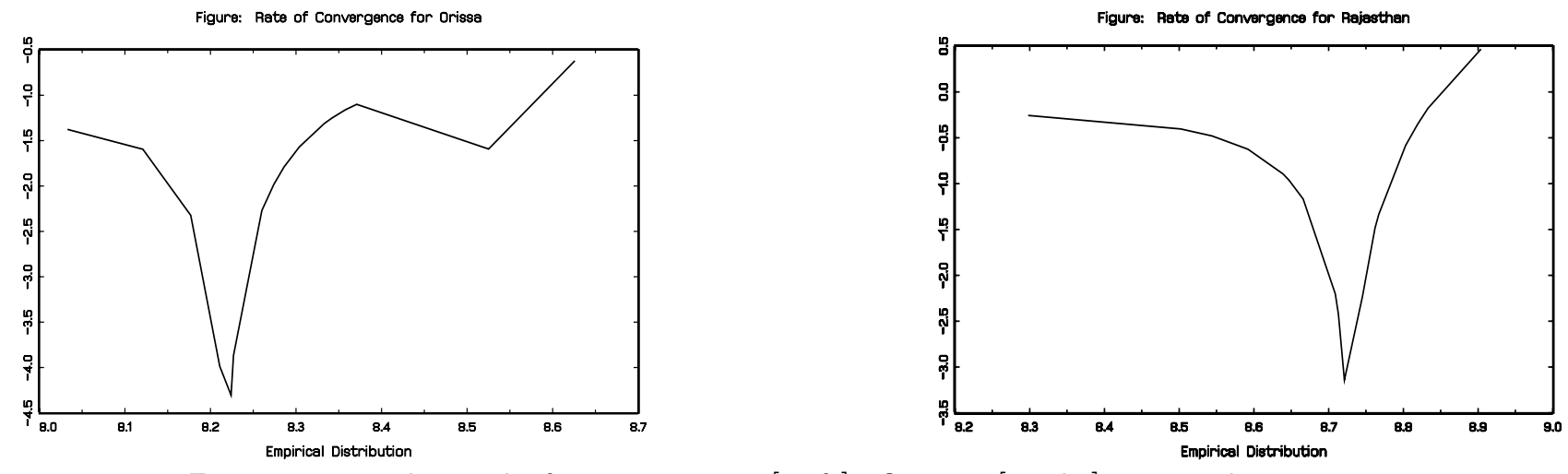

Figure 6: Local speed of convergence. [Left]: Orissa. [Right]: Rajasthan
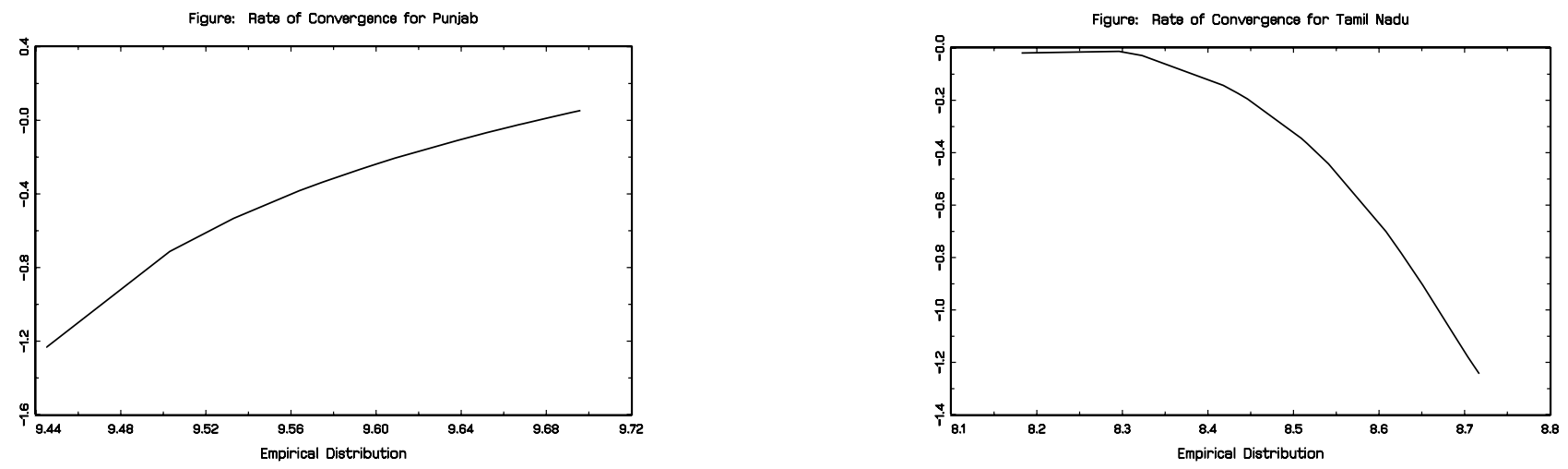

Figure 7: Local speed of convergence. [Left]: Punjab. [Right]: Tamil Nadu 

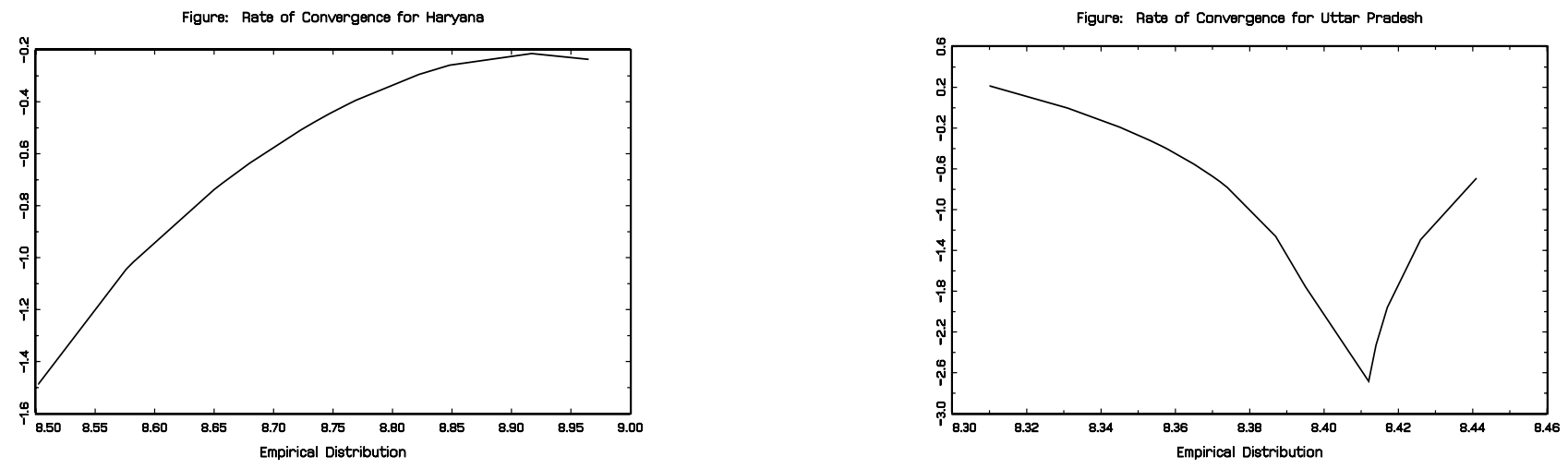

Figure 8: Local speed of convergence. [Left]: Haryana. [Right]: Uttar Pradesh

Figure: Rate of Convergence for West Bengal

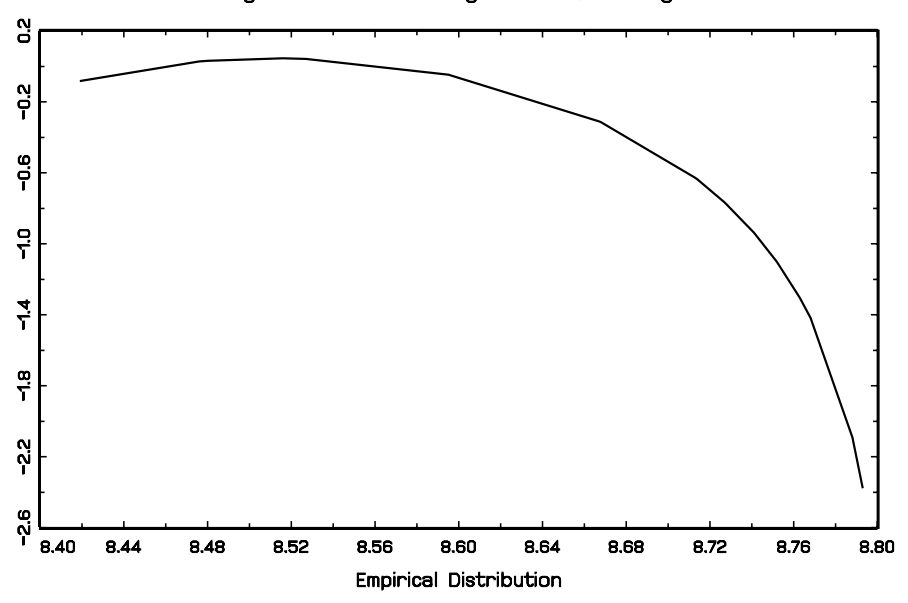

Figure 9: Local speed of convergence: West Bengal 



\section{WORKING PAPERS DE L'AFC}

\section{Année 2012}

WP2012-1

WP2012-2

WP2012-3

WP2012-4

WP2012-5

WP2012-6

WP2012-7

WP2012-8

WP2012-9

LuCa PENSIEROSO

"The Great Depression in Belgium: an Open-Economy Analysis"

Amélie CHARLES, Olivier DARNÉ, Claude DIEBOLT, Laurent FERRARA

"A New Monthly Chronology of the US Industrial Cycles in the Prewar Economy"

\section{Charlotte LE CHAPELAIN}

"Allocation des talents et accumulation de capital humain en France de la fin du XIXe siècle"

Claude DIEBOLT, Mamoudou TOURÉ, Jamel TRABELSI

"Monetary Credibility Effects on Inflation Dynamics:

A Macrohistorical Case Study"

\section{Thi Hong Van HOANG}

"Has Gold been a Hedge against Inflation in France from 1949 to 2011? Empirical Evidence of the French Specificity"

\section{Georges PRAT}

"Equity Risk Premium and Time Horizon: What do the U.S. Secular Data Say?"

\section{Suchit ARORA}

"Understanding Aging during the Epidemiologic Transition"

Alexandru MINEA, Antoine PARENT

"Is High Public Debt Always Harmful to Economic Growth? Reinhart and Rogoff and some Complex Nonlinearities"

\section{Claude DIEBOLT, Antoine PARENT}

"Property Rights and Early Colonization in Algeria:

The Astonishing Travel Stories of Two Precursors, Tocqueville $(1837,1841)$ and Juglar (1853)"

\section{WP2012-10 \\ Mamata PARHI, Claude DIEBOLT, Tapas MISHRA, Prashant} GUPTA

"Convergence Dynamics of Output: Do stochastic Shocks and Social Polarization Matter?"

WP2012-11 Thierry AIMAR, Francis BISMANS, Claude DIEBOLT "Economic Cycles: A Synthesis"

WP2012-12 Claude DIEBOLT

"The Cliometric Voice"
La liste complète des Working Papers est disponible sur le site www.cliometrie.org 